\title{
Environmental Policy and Social Efficiency under Free Entry
}

\author{
Ting-Chung Tsai ${ }^{1}$, Shih-Shen Chen², Yi-Shan Lư ${ }^{3}$, Chu-Chuan Hsu ${ }^{4}$, Jen-Yao Lee \\ ${ }^{1}$ National Kaohsiung University of Science and Technology, Chinese Taipei \\ ${ }^{2}$ Department of International Business and Trade, Shu-Te University, Chinese Taipei \\ ${ }^{3}$ Management School, Kunming University of Science and Technology, Kunming, China \\ ${ }^{4}$ Department of Marketing and Logistics Management, YuDa University of Science and Technology, Chinese Taipei \\ ${ }^{5}$ National Kaohsiung University of Science and Technology, Chinese Taipei \\ Email: *edison9@ydu.edu.tw
}

How to cite this paper: Tsai, T.-C., Chen, S.-S., Lu, Y.-S., Hsu, C.-C and Lee, J.-Y. (2019) Environmental Policy and Social Efficiency under Free Entry. Modern Economy, 10, 2110-2119.

https://doi.org/10.4236/me.2019.109132

Received: July 29, 2019

Accepted: September 20, 2019

Published: September 23, 2019

Copyright () 2019 by author(s) and Scientific Research Publishing Inc. This work is licensed under the Creative Commons Attribution International License (CC BY 4.0).

http://creativecommons.org/licenses/by/4.0/

\begin{abstract}
In this paper, we first show that if the firm's production leads to environmental damage and the government does not implement any environmental policy by using a two-stage game model, the "excess-entry" theorem holds. We then show that entry can be socially insufficient in the presence of production externality and policy mix is needed for pollution control in oligopoly industry with endogenous market structure. Hence, the anti-competitive entry regulation policy suggested by the "excess-entry" theorem does not always hold.
\end{abstract}

\section{Keywords}

Pollution, Environment, Emission Tax, Social Efficiency

\section{Introduction}

The wave of economic liberalization is being guided by the World Trade Organization around the world. Competition policies in many imperfect market sectors have facilitated the entry and removal of new entries. Competition policy plus many other intervention policies, such as subsidies, tariffs, environmental regulations, etc., should be reviewed from the perspective of long-term welfare improvement. For example, the welfare effects of environmental policies and liberalization policies and the implementation of these two policies should be the main focus of policy decisions.

Is free entry desirable for social efficiency? In an influential work, Mankiw and Whinston [1] showed that entry in oligopolistic markets is socially excessive 
in the presence of scale economies, thus providing the rationale for anti-competitive entry regulation in certain markets. This result, which is often referred to as "excess-entry" theorem has created significant interest in analyzing the welfare effects of entry in oligopolistic markets (see, Suzumura and Kiyono [2], Okuno-Fujiwara and Suzumura [3], Anderson et al. [4] and Fudenberg and Tirole [5], to name a few). In fact, whether or not entry is socially excessive is not merely an issue of simple academic interest [6]. In the practical dimension, governments in many countries take actions to foster or deter entry into particular industries. For example, in the post-war period, preventing excessive entry was a guiding principle in the Japanese industrial policy (see, Suzumura and Kiyono [2] and Suzumura [7]). Although it has been generally believed for a long time that entry is socially excessive in oligopolistic industries with scale economies ${ }^{1}$, Ghosh and Morita [8] [9] showed concern to the "excess-entry" theorem in industries characterized by vertical relationship. They demonstrated that entry is socially insufficient instead of excessive in a vertical structure where both the downstream and the upstream sectors have market powers. Wang et al. [14] demonstrated that if the number of domestic private firms is small, an import subsidy may be chosen and the optimal privatization policy is full privatization. They also showed that the long-run degree of privatization is larger than the short-run one, and the long-run tariff rate is smaller than the short-run tariff if and only if the entry cost of domestic private firms is sufficiently low. Furthermore, as long as the entry cost is relatively lower, domestic entry is socially excessive whether it is free trade or the domestic government imposes the tariff policy. Suzumura [15] provided an excellent review of the excess entry theorem 25 years later, since it was first argued by Mankiw and Whinston, and Suzumura and Kiyono [1].

Is free entry desirable for social efficiency in a pollution industry? We see that in those papers which addressed the effects of environmental policy mostly focused on how it affects profits, environmental damage and social welfare in an oligopoly model with a fixed number of firms, but even allowing free entry it did not asking whether free entry is desirable or not for social efficiency. On early studies of environmental policies in oligopolistic framework, Simpson [16] derived the optimal pollution for a Cournot duopoly with homogeneous products and found that if firms have different production costs, the optimal tax rate may exceed the marginal damage. Katsoulacos and Xepapadeas [17] proved that the tax rate is higher than the marginal damage, when the number of firms corresponds to the second best optimum. Damania [18] investigated the effects of an emissions tax on the incentives for oligopolists to acquire alternative pollution abatement technologies in the context of a repeated game, and demonstrated that there are circumstances in which firms may reject the option of acquiring ${ }^{1}$ Recent works show that: 1) Entry can be insufficient in an oligopolistic market with scale economies if there are vertical relationships [8] [9], 2) Spatial competition [10] [11], 3) Technology licensing [12] and 4. Market structure [13]. These works show that along with business stealing effects, entry creates further effects by either affecting the input prices, technologies, increasing the elasticity of demand or market leadership. 
pollution abatement equipment, even when this lowers their production costs. Yin [19] examined corrective taxes under oligopoly with inter-firm externalities and pollution abatement, and showed that when externalities are substantial and/or the number of polluters is large, effluent levies on these firms do not necessarily result in a deadweight loss. Lahiri and Ono [20] showed that in a polluting oligopoly with homogenous goods, when the number of firms is fixed, 1) a relative emission standard is welfare-superior to an emission-equivalent emission tax, and 2) an emission tax is emission-superior to a welfare-equivalent relative emission standard. Under free entry and exit, the results are just the opposite when the inverse demand function is concave. Cato [21] investigated optimal schemes for refunding the emission tax in a free-entry market and showed that in contrast to the case of two-part tax-refund policy under no entry, the first-best outcome is always attained even if it is impossible to obtain subsidies from outside. Fujiwara [22] constructed a model of polluting oligopoly with product differentiation, considering how product differentiation, together with the presence and absence of free entry, affects optimal pollution tax/subsidy policies. The sign of the short- and long-run optimal pollution taxes are highly sensitive to the parameter measuring product differentiation as well as the presence of free entry. Hsu et al. [23] investigated the optimal environmental and privatization policies at regulated entry and free entry in a mixed oligopoly, wherein firms produce differentiated goods with environmental damage that is measured by government and observed by consumers. They showed that 1) in both mixed and private oligopoly with regulated entry or free entry, the emission tax/subsidy could be provided, and 2) the number of the private firms at free-entry differentiated oligopoly after the public firm is privatized is socially inefficient even though the consumers have more choice of product varieties. Lain et al. [24] considered two scenarios in which the government chooses the optimal level of tax before or after firms enter the market. They found that in both cases, the emission tax/subsidy could be provided and the optimal level of tax is always less than the marginal environmental damage. The most important result is that, regardless of the degree of the consumers' environmental cognition, the ex-post taxation case yields a lower level of tax and a larger number of firms than does ex-ante taxation.

In this paper, we show that if the firm's production leads to environmental damage and the government does not implement any environmental policy, the "excess-entry" theorem holds in a pollution industry. However, the anti-competitive entry regulation policy suggested by the "excess-entry" theorem does not always hold if the environmental policy is implemented. Furthermore, policy mix is needed for pollution control in an oligopoly industry with endogenous market structure. ${ }^{2}$

This paper is organized as follows. Section 2 provides the basic model and examines the case of no environmental policy in an oligopoly with restricted en-

${ }^{2}$ Lehmann [25] provides a review of economic studies analyzing the use of multiple policies- a so-called policy mix- to cope with single pollution problerms. 
try and at free entry. Section 3 does a similar analysis when the environmental policy is implemented. Section 4 further analyzes the policy implication of excess entry in the model when the firms also decide the abatement level in addition to the output decision. Section 5 presents concluding remarks.

\section{The Basic Model}

Assume the market demand is $P=a-Q$, and there are $n$ identical firms producing homogeneous good in the market. Each firm produces $q_{i}$, and the total output is $Q=\sum q_{i}$. The production of this good leads to pollution $e_{i}=\theta q_{i}{ }^{3}$ Environmental damage is measured by the quadratic form $E D=\left(\sum e_{i}\right)^{2} / 2$.

The cost function is measured by a quadratic form, $q_{i}^{2} / 2$ for the firms, and the profit functions are,

$$
\pi_{i}=P q_{i}-\frac{q_{i}^{2}}{2}-f^{2}
$$

where $f^{2}$ is the fixed cost of market entry.

In the absence of environmental policy, the social welfare is defined as

$$
W=C S+\sum \pi_{i}-E D
$$

where $C S=Q^{2} / 2$.

Using a two-stage game model, in the first stage, the firms decide whether to enter or not to enter. The second stage is the monopolistic firm's production decisions. We solve the maximization problems by backward induction under the premise of Subgame Perfect Nash equilibrium (SPNE).

\subsection{Regulated Entry}

All the firms choose output only; we differentiate Equation (1) with respect to $q_{i}$ and obtain that

$$
\frac{\partial \pi_{i}}{\partial q_{i}}=a-(n+2) q_{i}=0
$$

From the above first-order conditions, we obtain the short-run equilibrium results with regulated entry

$$
q_{i}^{*}=\frac{a}{2+n}, \quad \pi_{i}^{*}=\frac{3 a^{2}}{2(2+n)^{2}}, \quad C S_{i}^{*}=\frac{a^{2} n^{2}}{2(2+n)^{2}}, W^{*}=\frac{a^{2} n\left(3+n-n \theta^{2}\right)}{2(2+n)^{2}} .
$$

\subsection{Free Entry and Social Efficiency}

Consider the case where entry occurs in the market, firm is net profit is given by

$$
\pi_{i}=\frac{3 a^{2}}{2(2+n)^{2}}-f^{2} \text {. }
$$

The free entry equilibrium number of firms is given by

$$
\pi_{i}=\frac{3 a^{2}}{2(2+n)^{2}}-f^{2}=0, \text { or } \frac{3 a^{2}}{2(2+n)^{2}}=f^{2}
$$

${ }^{3}$ See Ulph [26] for the specification of production pollution. 
The social welfare is given as

$$
W=\frac{a^{2} n\left(3+n-n \theta^{2}\right)}{2(2+n)^{2}}-n f^{2}
$$

The welfare-maximizing number of firms is given by

$$
\frac{\partial W}{\partial n}=0, \Rightarrow \frac{a^{2}\left(6+n-4 n \theta^{2}\right)}{2(2+n)^{3}}=f^{2}
$$

Defining $\Delta=$ [LHS of (6) - LHS of (4)], we have

$$
\Delta=\frac{-a^{2} n\left(1+2 \theta^{2}\right)}{(2+n)^{3}}
$$

Entry is socially excessive if and only if $\Delta<0 .{ }^{4}$ We find that $\Delta<0$, suggesting excessive entry when the firm's production leads to environmental damage. The reasoning is that if the firm's production leads to environmental damage and the government does not implement any environmental policy, then the total output will be too much for social optimum which echo with the excessive entry argument of Mankiw and Whinston [1] in a non-pollution industry. Environmental damage leads to a decline of social welfare and the number of firms at free entry is socially excessive. The policy implication is entry regulation when the environmental policy is not imposed.

\section{Environmental Tax}

In this section, we assume each firm has to pay an environmental tax $t$ per unit of pollutant emitted and the profit of firm $i$ is given by

$$
\pi_{i}=P q_{i}-\frac{q_{i}^{2}}{2}-t e_{i}-f^{2}
$$

The objective of the government is to maximize social welfare, which is expressed as

$$
W=C S+\sum \pi_{i}-E D+T
$$

where $T=t \sum e_{i}$ denotes tax revenues collected by the government.

\subsection{Regulated Entry}

All the firms choose output and differentiate Equation (1') with respect to $q_{i}$, and obtain that

$$
\frac{\partial \pi_{i}}{\partial q_{i}}=a-(n+2) q_{i}-t \theta=0
$$

From the above first-order conditions, we need the condition $a-t \theta>0$ for having positive output and obtain the short-run equilibrium results with regulated entry

${ }^{4}$ In Mukherjee [13], the free entry equilibrium number of firms and the welfare-maximizing number of firms is compared by showing the sign of $\Delta$. 


$$
\begin{gathered}
q_{i}^{*}=\frac{a-t \theta}{2+n}, \pi_{i}^{*}=\frac{3(a-t \theta)^{2}}{2(2+n)^{2}}, C S_{i}^{*}=\frac{(a-t \theta)^{2} n^{2}}{2(2+n)^{2}}, \\
W=\frac{n(a-t \theta)\left\{a\left[3+n\left(1-\theta^{2}\right)\right]+t \theta\left(1+n-n \theta^{2}\right)\right\}}{2(2+n)^{2}} .
\end{gathered}
$$

\subsection{Free Entry and Social Efficiency}

Consider the case where entry occurs in the market, firm $i$ s net profit is given by

$$
\pi_{i}=\frac{3(a-t \theta)^{2}}{2(2+n)^{2}}-f^{2} .
$$

The free entry equilibrium number of firms is given by

$$
\pi_{i}=\frac{3(a-t \theta)^{2}}{2(2+n)^{2}}-f^{2}=0, \text { or } \frac{3(a-t \theta)^{2}}{2(2+n)^{2}}=f^{2}
$$

The social welfare is given as

$$
W=\frac{n(a-t \theta)\left\{a\left[3+n\left(1-\theta^{2}\right)\right]+t \theta\left(1+n-n \theta^{2}\right)\right\}}{2(2+n)^{2}}-n f^{2}
$$

The welfare-maximizing number of firms is given by

$$
\frac{\partial W}{\partial n}=0, \Rightarrow \frac{(a-t \theta)\left\{t \theta\left[2+n\left(3+4 \theta^{2}\right)\right]+a\left[6+n\left(1-4 \theta^{2}\right)\right]\right\}}{2(2+n)^{3}}=f^{2}
$$

Defining $\Delta=$ [LHS of (11) - LHS of (9)], we have

$$
\Delta=\frac{-(a-t \theta)\left\{n\left(1+2 \theta^{2}\right)(a-t \theta)-2 t \theta(2+n)\right\}}{(2+n)^{3}}
$$

We find that $\Delta<(>) 0$ if $t<(>) \hat{t} \equiv \frac{a n\left(1+2 \theta^{2}\right)}{\theta\left[2(2+n)+n\left(1+2 \theta^{2}\right)\right]}$, suggesting entry is socially excessive (insufficient) depending on the level of environmental taxes.

Proposition 1. If $t<(>) \hat{t}$, entry of the firms is socially excessive (insufficient).

Proposition 1 shows that entry can be socially insufficient in the presence of production externality. Hence, the anti-competitive entry regulation policy suggested by the "excess-entry" theorem does not always hold. It points out that environmental taxes should be designed properly and combined with (anti-)competition policy to correct multiple distortions, market distortion and production externality. Hence, a higher environmental tax should be combined with entry-promotion policy and vice versa from the standpoint of social welfare maximization.

\section{Environmental Tax with Pollution Abatement}

In this section, we suppose that firm $i$ chooses pollution abatement level $a_{i}$, the 
emission level of each firm is $e_{i}=\theta q_{i}-a_{i}$ and each firm has to pay an environmental tax $t$ per unit of pollutant emitted. The cost of pollution abatement of firm $i$ is $a_{i}^{2} / 2$. The profit of firm $i$ is given by

$$
\pi_{i}=P q_{i}-\frac{q_{i}^{2}}{2}-\frac{a_{i}^{2}}{2}-t e_{i}-f^{2}
$$

\subsection{Regulated Entry}

We differentiate Equation (1") with respect to $q_{i}$ and $a_{i}$, and obtain that

$$
\begin{gathered}
\frac{\partial \pi_{i}}{\partial q_{i}}=a-(n+2) q_{i}-t \theta=0 \\
\frac{\partial \pi_{i}}{\partial a_{i}}=t-a_{i}=0
\end{gathered}
$$

Equation (14) shows that all the firms abate pollution to the point where marginal abatement cost equals the tax. From the above first-order conditions, we obtain the short-run equilibrium results with regulated entry

$$
\begin{array}{r}
q_{i}^{*}=\frac{a-t \theta}{2+n}, \pi_{i}^{*}=\frac{3(a-t \theta)^{2}+(2+n)^{2} t^{2}}{2(2+n)^{2}}, C S_{i}^{*}=\frac{(a-t \theta)^{2} n^{2}}{2(2+n)^{2}}, \\
W^{*}=\frac{n\left\{a^{2}\left(3+n-n \theta^{2}\right)+2 a t \theta\left[-1+n\left(2+n+\theta^{2}\right)\right]-t^{2}\left\{4+\theta^{2}+n\left[8+5 n+n^{2}+(5+2 n) \theta^{2}+\theta^{4}\right]\right\}\right\}}{2(2+n)^{2}} .
\end{array}
$$

\subsection{Free Entry and Social Efficiency}

Consider the case where entry occurs in the market, firm is net profit is given by

$$
\pi_{i}=\frac{3(a-t \theta)^{2}+(2+n)^{2} t^{2}}{2(2+n)^{2}}-f^{2} .
$$

The free entry equilibrium number of firms in the pollution industry is given by

$$
\pi_{i}=\frac{3(a-t \theta)^{2}+(2+n)^{2} t^{2}}{2(2+n)^{2}}-f^{2}=0, \text { or } \frac{3(a-t \theta)^{2}+(2+n)^{2} t^{2}}{2(2+n)^{2}}=f^{2}
$$

The social welfare is given as

$$
W=\frac{n\left\{a^{2}\left(3+n-n \theta^{2}\right)+2 a t \theta\left[-1+n\left(2+n+\theta^{2}\right)\right]-t^{2}\left\{4+\theta^{2}+n\left[8+5 n+n^{2}+(5+2 n) \theta^{2}+\theta^{4}\right]\right\}\right\}}{2(2+n)^{2}}-n f^{2}
$$

The welfare-maximizing number of firms is given by

$$
\frac{\partial W}{\partial n}=0, \Rightarrow W^{\prime}=f^{2}
$$

Defining $\Delta=$ [LHS of (17) - LHS of (15)], we have

$$
\Delta=-\frac{a^{2}\left(n+2 n \theta^{2}\right)+t^{2}\left\{(1+n)(2+n)^{3}+\left[4+n\left(11+6 n+n^{2}\right)\right] \theta^{2}+2 n \theta^{4}\right\}-a t \theta\left\{4+n\left[n(6+n)+4\left(3+\theta^{2}\right)\right]\right\}}{(2+n)^{3}}
$$


We find that $\Delta>(<) 0$ if

$t>(<) \bar{t}=\frac{a \theta\left\{4+n\left[n(6+n)+4\left(3+\theta^{2}\right)\right]\right\}-a(2+n) \sqrt{-4 n(1+n)(2+n)+\left(-2+n^{2}\right)^{2} \theta^{2}}}{2 n\left(2+n+\theta^{2}\right)\left[(2+n)^{2}+2 \theta^{2}\right]-4 \theta^{2}}$

suggesting entry is socially excessive (insufficient) depending on the level of environmental taxes. Similar to the reasoning provided for Proposition 1, the possibility for socially insufficient is that if the environmental tax is set too high, the firms need to increase their abatement level which makes the industry profit down and the number of firm at free entry is smaller, the entry is socially insufficient. Under such circumstance, the policy implication is not entry regulation but rather entry promotion coupled with a stringent environmental policy from the standpoint of social welfare maximization.

Regardless of whether firms have conducted pollution prevention, it points out that environmental taxes should be designed properly and combined with (anti-)competition policy to correct multiple distortions, market distortion and production externality.

\section{Conclusion}

In this paper, we showed that if the firm's production leads to environmental damage and the government does not implement any environmental policy, the "excess-entry" theorem holds in a pollution industry. However, the anti-competitive entry regulation policy suggested by the "excess-entry" theorem does not always hold if the environmental policy is implemented. In particular, if the environmental tax is set too high, the firms need to increase their abatement level which makes the industry profit down and the number of firm at free entry is smaller, the entry is socially insufficient. The policy implication is not entry regulation but rather entry promotion coupled with a stringent environmental policy. Hence, policy mix is needed for pollution control in oligopoly industry with endogenous market structure.

\section{Conflicts of Interest}

The authors declare no conflicts of interest regarding the publication of this paper.

\section{References}

[1] Mankiw, N.G. and Whinston, M.D. (1986) Free Entry and Social Inefficiency. Rand Journal of Economics, 17, 48-58. https://doi.org/10.2307/2555627

[2] Suzumura, K. and Kiyono, K. (1987) Entry Barriers and Economic Welfare. Review of Economic Studies, 54, 157-167. https://doi.org/10.2307/2297451

[3] Okuno-Fujiwara, M. and Suzumura, K. (1993) Symmetric Cournot Oligopoly and Economic Welfare: A Synthesis. Economic Theory, 3, 43-59. https://doi.org/10.1007/BF01213691

[4] Anderson, S.P., de Palma, A. and Nesterov, Y. (1995) Oligopolistic Competition and the Optimal Provision of Products. Econometrica, 63, 1281-1301. 
https://doi.org/10.2307/2171770

[5] Fudenberg, D. and Tirole, J. (2000) Pricing a Network Good to Deter Entry. Journal of Industrial Economics, 48, 373-390. https://doi.org/10.1111/1467-6451.00129

[6] Vives, X. (1988) Sequential Entry, Industry Structure and Welfare. European Economic Review, 32, 1671-1687. https://doi.org/10.1016/0014-2921(88)90025-6

[7] Suzumura, K. (1995) Competition, Commitment and Welfare. Clarendon Press, Oxford.

[8] Ghosh, A. and Morita, H. (2007) Social Desirability of Free Entry: A Bilateral Oligopoly Analysis. International Journal of Industrial Organization, 25, 925-934. https://doi.org/10.1016/j.ijindorg.2007.02.002

[9] Ghosh, A. and Morita, H. (2007) Free Entry and Social Efficiency under Vertical Oligopoly. Rand Journal of Economics, 38, 539-552.

https://doi.org/10.1111/j.1756-2171.2007.tb00083.x

[10] Matsumura, T. and Okamura, M. (2006) A Note on the Excess Entry Theorem in Spatial Markets. International Journal of Industrial Organization, 24, 1071-1076. https://doi.org/10.1016/j.ijindorg.2006.03.005

[11] Matsumura, T. and Okamura, M. (2006) Equilibrium Number of Firms and Economic Welfare in a Spatial Price Discrimination Model. Economics Letters, 90, 396-401. https://doi.org/10.1016/j.econlet.2005.09.004

[12] Mukherjee, A. and Mukherjee, S. (2008) Excess-Entry Theorem: The Implications of Licensing. The Manchester School, 76, 675-689. https://doi.org/10.1111/j.1467-9957.2008.01088.x

[13] Mukherjee, A. (2011) Social Efficiency of Entry with Market Leaders. Journal of Economics and Management Strategy, 21, 431-444.

[14] Wang, F.S., Lee, J.Y. and Hsu, C.C. (2014) Privatization, Foreign Competition, and Social Efficiency of Free Entry. International Review of Economics and Finance, 31, 138-147. https://doi.org/10.1016/j.iref.2014.01.017

[15] Suzumura, K. (2012) Excess Entry Theorem after 25 Years. Japanese Economic Review, 63, 152-170. https://doi.org/10.1111/j.1468-5876.2012.00565.x

[16] Simpson, R.D. (1995) Optimal Pollution Taxation in a Cournot Duopoly. Environmental and Resource Economics, 6, 359-369. https://doi.org/10.1007/BF00691819

[17] Katsoulacos, Y. and Xepapadeas, A. (1995) Environmental Policy under Oligopoly with Endogenous Market Structure. Scandinavian Journal of Economics, 97, 411-420. https://doi.org/10.2307/3440871

[18] Damania, D. (1996) Pollution Taxes and Pollution Abatement in an Oligopoly Supergame. Journal of Environmental Economics and Management, 30, 323-336. https://doi.org/10.1006/jeem.1996.0022

[19] Yin, X. (2003) Corrective Taxes under Oligopoly with Inter-Firm Externalities. Environmental and Resource Economics, 26, 269-277. https://doi.org/10.1023/A:1026360104591

[20] Lahiri, S. and Ono, Y. (2007) Relative Emission Standard versus Tax under Oligopoly: The Role of Free Entry. Journal of Economics, 91, 107-128. https://doi.org/10.1007/s00712-006-0243-1

[21] Cato, S. (2010) Emission Taxes and Optimal Refunding Schemes with Endogenous Market Structure. Environmental and Resource Economics, 46, 275-280. https://doi.org/10.1007/s10640-009-9340-2

[22] Fujiwara, K. (2009) Environmental Policies in a Differentiated Oligopoly Revisited. Resource and Energy Economics, 31, 239-247. 
https://doi.org/10.1016/j.reseneeco.2009.03.002

[23] Hsu, C.C., Lee, J.Y. and Wang, L.F.S. (2017) Consumers Awareness and Environmental Policy in Differentiated Mixed Oligopoly. International Review of Economics and Finance, 51, 444-454. https://doi.org/10.1016/j.iref.2017.07.001

[24] Lain, X., Gong, Q. and Wang, L.F.S. (2018) Consumer Awareness and Ex-Ante versus Ex-Post Environmental Policies Revisited. International Review of Economics and Finance, 55, 68-77. https://doi.org/10.1016/j.iref.2018.01.014

[25] Lehmann, P. (2010) Justifying a Policy Mix for Pollution Control: A Review of Economic Literature. Journal of Economic Surveys, 26, 71-97.

https://doi.org/10.1111/j.1467-6419.2010.00628.x

[26] Ulph, A. (1996) Environmental Policy and International Trade When Governments and Producers Act Strategically. Journal of Environmental Economics and Management, 30, 265-281. https://doi.org/10.1006/jeem.1996.0018 